\title{
Synthesis, characterization and antimicrobial activity of important heterocyclic acrylic copolymers
}

\author{
H. J. Patel, M. G. Patel, A. K. Patel, K. H. Patel, R. M. Patel* \\ Department of Chemistry, Sardar Patel University, Vallabh Vidyanagar, Gujarat, India
}

Received 15 July 2008; accepted in revised form 14 September 2008

\begin{abstract}
The acrylate monomer, 7-acryloyloxy-4-methyl coumarin (AMC) has been synthesized by reacting 7-hydroxy4-methyl coumarin, with acryloyl chloride in the presence of $\mathrm{NaOH}$ at $0-5^{\circ} \mathrm{C}$. Copolymers of 7-acryloyloxy-4-methyl coumarin (AMC) with vinyl acetate (VAc) were synthesized in DMF (dimethyl formamide) solution at $70 \pm 1{ }^{\circ} \mathrm{C}$ using $2,2^{\prime}-$ azobisisobutyronitrile (AIBN) as an initiator with different monomer-to-monomer ratios in the feed. The copolymers were characterized by Fourier transform infra red (FTIR) spectroscopy. The copolymer composition was evaluated by ${ }^{1} \mathrm{H}-\mathrm{NMR}$ (proton nuclear magnetic resonance) and was further used to determine reactivity ratios. The monomer reactivity ratios for AMC $\left(M_{1}\right)$-VAc $\left(M_{2}\right)$ pair were determined by the application of conventional linearization methods such as Fineman-Ross $\left(r_{1}=0.6924 ; r_{2}=0.6431\right)$, Kelen-Tüdős $\left(r_{1}=0.6776 ; r_{2}=0.6374\right)$ and extended Kelen-Tüdős $\left(r_{1}=0.6657 ; r_{2}=0.6256\right)$. Thermo gravimetric analysis showed that thermal decomposition of the copolymers occurred in single stage in the temperature range of $263-458^{\circ} \mathrm{C}$. The molecular weights of the polymers were determined using gel permeation chromatography. The homo and copolymers were tested for their antimicrobial properties against selected microorganisms.
\end{abstract}

Keywords: thermal properties, 7-hydroxy-4-methyl coumarin, ${ }^{1} \mathrm{H}-\mathrm{NMR}$, antimicrobial activity

\section{Introduction}

Copolymerization is one of the important techniques adopted in effecting systematic changes in the properties of the commercially important polymers. The copolymers of acrylic/methacrylic esters have been used for various industrial applications [1]. The chemical structure of a copolymer depends not only on the two-monomer units forming the macromolecule, but also on how such units are distributed along macromolecular chains. This distribution is a direct consequence of each monomer's reactivity in the copolymer molecule [2]. In case of radical copolymerization, the reactivity of a free radical depends on the nature of the side group linked to the radical carbon [3].

Many polymers with reactive functional groups are now being synthesized, tested and used not only for their macromolecular properties, but also for the properties of functional group. These groups provide an approach to a subsequent modification of the polymer for specific end application [4]. Czeh and coworkers synthesized acrylic pressure sensitve adhesives with the help of azo-prester radical initiators [5]. Pazhanisamy and coworkers synthesized copolymers of $\mathrm{N}$-cyclohexylacrylamide/ n-butyl acrylate. The resulting copolymers were characterized by FT-IR, NMR, DSC (differential scanning calorimetry) and TGA (thermogravimetric analysis). Reactivity ratios of the monomers were also computed [6]. There are several reports on acrylic polymers for use in binding of pigments as well as for antimicrobial coatings in textile industry $[7,8]$. 
Coumarin polymers possessing antimicrobial activity have not received considerable attention in the literature. However the reported coumarin polymers possess variety of functions and appear to be interesting. Although there is a huge number of reports on monomeric coumarin derivatives, there are only a few reports on coumarin polymers. Vinylated coumarins are used as polymerizable fluorescent brightening agents and, when copolymerized with acrylonitrile and methyl acrylate, they faded more slowly than copolymers of acrylonitrile and methylacrylate [9].

A novel blue luminescent polymer bearing coumarin pendants was prepared by Lu et al. [10]. Its luminescent properties were determined indicating that it had strong blue fluorescent properties and good film formation ability. This novel polymer can be used as a blue organic electroluminescent material (OELM) in organic electroluminescent devices. Chen and co-workers have studied the radical copolymerization behaviour of styrene with coumarin or 7-acetoxy coumarin [11]. Lindsay and co-workers [12] synthesized the copolymer of coumarin methacrylate with isobornylmethacrylate. These polymers showed tremendous non linear optical properties.

Due to various physiological and biochemical properties of coumarin, our interest was to synthesize acrylic copolymers containing coumarin side groups. Present work focuses on synthesis and characterization of 7-acryloyloxy-4-methyl coumarin (AMC) and its copolymers with vinyl acetate (VAc). Reactivity ratio values of the monomers were determined by various linearization techniques. TGA and GPC results are also included. The prepared copolymers were tested for their antimicrobial activity against various bacteria, fungi and yeast.

\section{Experimental}

\subsection{Materials}

Vinyl acetate (VAc) was freed of inhibitor by washing with $5 \% \mathrm{NaOH}$ and then with water several times. After being dried over anhydrous $\mathrm{Na}_{2} \mathrm{SO}_{4}$, it was distilled under reduced pressure. 2,2'-Azobis (iso butyronitrile) (AIBN) was recrystallized twice from methanol. 7-hydroxy-4-methyl coumarin and acryloyl chloride were synthesized as per reported procedure $[13,14]$. Fractionally distilled solvents were used in the reaction.

\subsection{Synthesis of 7-acryloyloxy-4-methyl coumarin (AMC)}

7-hydroxy-4-methyl coumarin $(0.1 \mathrm{~mol})$ dissolved in absolute alcohol $(250 \mathrm{ml})$, was placed along with sodium hydroxide $(0.1 \mathrm{~mol})$ in a two necked $500 \mathrm{ml}$ flask. With continuous stirring of the reaction mixture at $0-5^{\circ} \mathrm{C}$, freshly distilled acryloyl chloride $(0.11 \mathrm{~mol})$ was added slowly from an addition funnel. An hour after the completion of addition, the contents were stirred for 90 minutes and were poured into crushed ice water mixture where a white colored monomer was separated out. It was filtered, washed with cold water and dried. Further the monomer was recrystallized from methanol (yield: $89 \%$, m.p.: $122^{\circ} \mathrm{C}$ ). The formation of the monomer was confirmed by FT-IR (Figure 1a) and ${ }^{1} \mathrm{H}-\mathrm{NMR}$ spectra (Figure $1 \mathrm{~b}$ ).
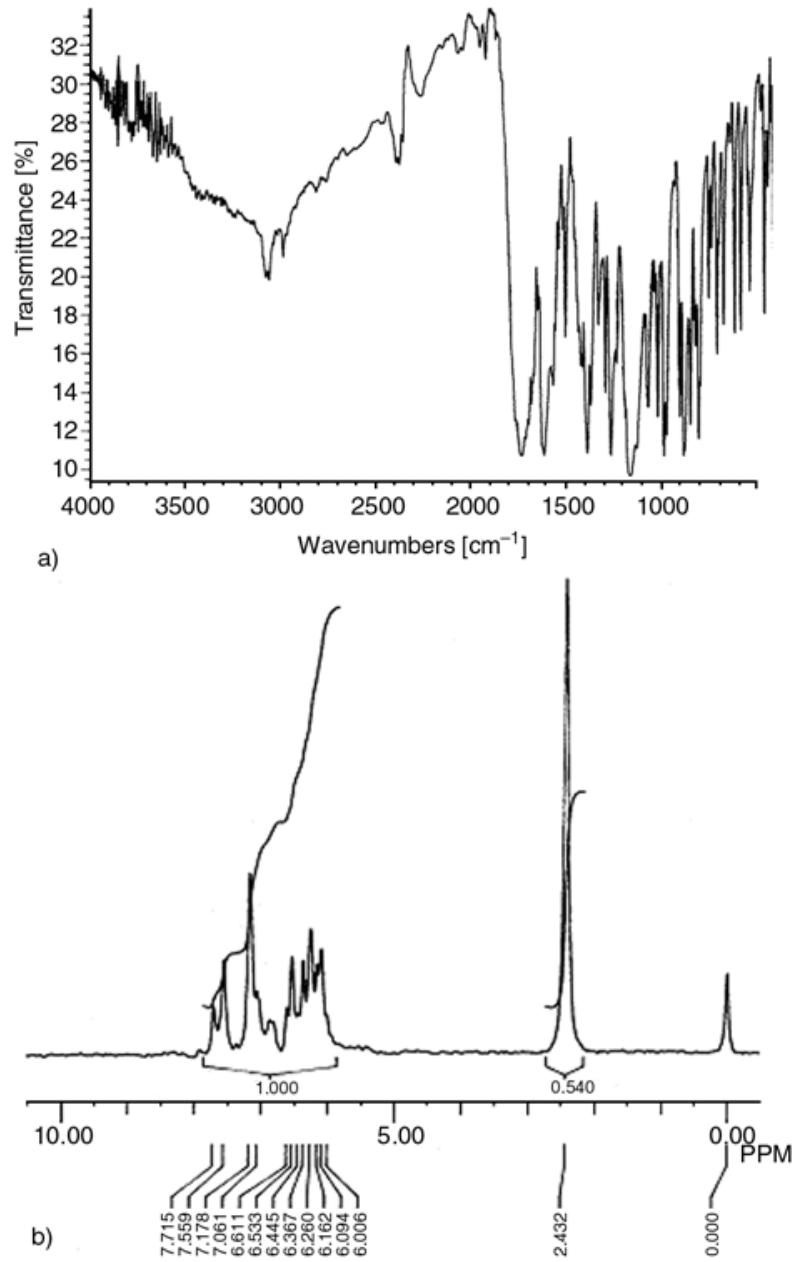

Figure 1. Characterization of AMC (a) FT-IR and (b) ${ }^{1} \mathrm{H}-\mathrm{NMR}$ 
IR $\left(\mathrm{KBr}, \mathrm{cm}^{-1}\right): 3073$ (-CH stretching vibration of the aromatic ring), $2986\left(-\mathrm{CH}_{3}\right), 1737$ (broad, $\mathrm{C}=\mathrm{O}$ of acrylate and of coumarin moiety), $1630(\mathrm{C}=\mathrm{C})$, 1240 (asymmetric C-O-C), 1142 (symmetric $\mathrm{C}-\mathrm{O}-\mathrm{C}), 890$ (-CH bending mode of vinyl group), 730 (rocking mode of vinyl group).

${ }^{1} \mathrm{H}-\mathrm{NMR}(\delta[\mathrm{ppm}])(60 \mathrm{MHz}): 6.26(1 \mathrm{H},-\mathrm{CH}=)$, $2.43\left(3 \mathrm{H}, \mathrm{CH}_{3}\right), 6.36(2 \mathrm{H}$, non-equivalent methylene protons), 7.06-7.72 (3H, aromatic protons).

\subsection{Homopolymerization of AMC}

This was carried out using solution polymerization technique. AIBN (1\% wt of monomer) was added to $2 \mathrm{~g}$ of AMC dissolved in $10 \mathrm{ml}$ of DMF taken in a polymerization tube. The content was degassed with nitrogen and kept at $70 \pm 1^{\circ} \mathrm{C}$ in a water bath for 5 hours. The polymer was precipitated by pouring the contents of the polymerization tube into excess methanol. The resultant precipitate was filtered and dried in vacuum at $40^{\circ} \mathrm{C}$.

\subsection{Copolymerization of AMC with VAc}

Copolymerization was carried out by solution polymerization technique using DMF as a solvent and AIBN as a free radical initiator at $70 \pm 1^{\circ} \mathrm{C}$ under nitrogen atmosphere. Appropriate amounts of AMC, VAc, AIBN (1 wt $\%$ of the monomers) and DMF (Table 1) were mixed in a polymerization tube, degassed with nitrogen and kept in a thermostat $\left(70 \pm 1^{\circ} \mathrm{C}\right)$ for a definite period of time so as to maintain the conversion below $10 \%$. Then the contents were precipitated by pouring into excess methanol and filtered. The precipitate was purified by dissolving in dimethyl formamide and reprecipitated using methanol, filtered and dried in a vacuum oven at $40^{\circ} \mathrm{C}$. Figure 2 shows the copolymerization of AMC with VAc.

\subsection{Measurements}

IR spectra of the monomer and polymers were recorded on Nicolet 400 D FT-IR spectrometer using $\mathrm{KBr}$ pellets. ${ }^{1} \mathrm{H}-\mathrm{NMR}$ spectra of the samples were run on a Hitachi-R-1500 permanent magnet $60 \mathrm{MHz}$ spectrophotometer. TGA curves of the homo and copolymers were recorded on TA instrument (USA) 2690 thermogravimetric analyzer in nitrogen atmosphere at a heating rate of $10^{\circ} \mathrm{C} / \mathrm{min}$. The number average and weight average molecular weight of the polymers were determined by gel permeation chromatography using polystyrene as standard and DMF is used as eluent at $1.0 \mathrm{ml} / \mathrm{min}$ flow rate.

\subsection{Antimicrobial activity}

The homo and copolymers obtained were tested against different bacterial strains (Bacillus subtilis, Escherichia coli and Staphylococcus citreus), fungal strains (Aspergillus niger, Sporotichum pulveruletum and Trichocerma lignorum) and yeast strains (Candida utilis, Saccharomyces cerevisiac

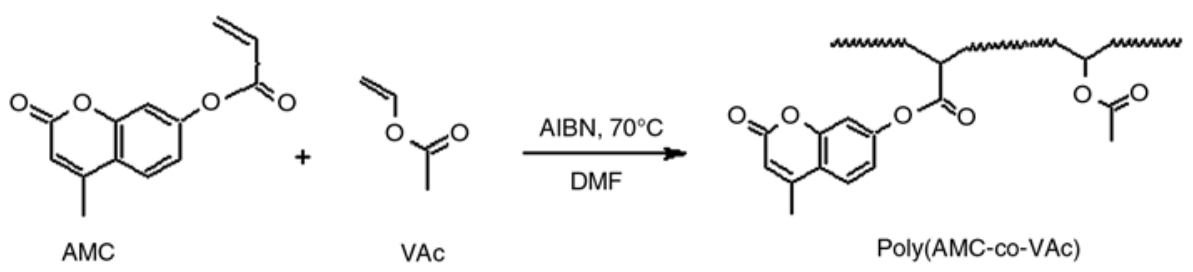

Figure 2. Reaction scheme of $\mathrm{P}(\mathrm{AMC}-\mathrm{co}-\mathrm{VAc})$

Table 1. Copolymer composition data of AMC and VAc

\begin{tabular}{|c|c|c|c|c|c|c|c|}
\hline \multirow{2}{*}{$\begin{array}{c}\text { Polymer } \\
\text { No. }\end{array}$} & \multicolumn{2}{|c|}{ Mole fraction in feed } & \multicolumn{2}{|c|}{ Intensities of protons } & \multirow{2}{*}{$\mathbf{C}$} & \multicolumn{2}{|c|}{ Mole fraction in copolymer } \\
\hline & $\operatorname{AMC}\left(M_{1}\right)$ & VAc $\left(\mathbf{M}_{2}\right)$ & $\mathbf{I}_{\text {arom }}$ & $\mathbf{I}_{\text {alip }}$ & & $\operatorname{AMC}\left(\mathbf{m}_{1}\right)$ & VAc $\left(\mathbf{m}_{2}\right)$ \\
\hline 1 & 1.0 & - & - & - & - & 1.0 & - \\
\hline 2 & 0.5 & 0.5 & 34.81 & 148.76 & 0.234 & 0.508 & 0.492 \\
\hline 3 & 0.4 & 0.6 & 27.65 & 139.64 & 0.198 & 0.425 & 0.575 \\
\hline 4 & 0.3 & 0.7 & 21.38 & 131.97 & 0.162 & 0.344 & 0.656 \\
\hline 5 & 0.2 & 0.8 & 17.08 & 147.24 & 0.116 & 0.243 & 0.757 \\
\hline 6 & 0.1 & 0.9 & 13.49 & 201.34 & 0.067 & 0.139 & 0.861 \\
\hline 7 & - & 1.0 & - & - & - & - & 1.0 \\
\hline
\end{tabular}


and Pichia stipitis). The details of the experimental procedures have been reported in our earlier publication $[15,16]$.

\section{Results and Discussion}

Different homo and copolymers were obtained by the free radical solution polymerization technique. The mole fractions of AMC ranging from 0.5 to 0.1 in the feed were studied in a wide composition interval. The reaction time was selected in trials to give conversions less than $10 \%$ in order to satisfy the differential copolymerization equation. The monomeric units of the copolymer are shown in Figure 2. The data on the composition of the feed and copolymers are given in Table 1.

\subsection{Characterization of polymers}

\subsubsection{Solubility}

The homo and copolymers synthesized were soluble in chloroform, dimethyl formamide, dimethyl sulfoxide, toluene and tetrahydro furan. It is insoluble in n-hexane, acetone and hydroxyl group containing solvents such as methanol and ethanol.

\subsubsection{Infrared spectra}

The IR spectra of the homo and copolymers are shown in Figure 3. The two medium bands at 2966 and $2932 \mathrm{~cm}^{-1}$ may be attributed to the asymmetric and symmetric $\mathrm{C}-\mathrm{H}$ stretching vibration of methylene group where as, absorption at $1455 \mathrm{~cm}^{-1}$ may be due to bending vibration of $-\mathrm{CH}_{2}$ group. The strong absorptions at $1394 \mathrm{~cm}^{-1}$ may be traced due to in-plane bending vibrations of methyl and methylene groups. The broad band at $1736 \mathrm{~cm}^{-1}$ is assigned to $\mathrm{C}=\mathrm{O}$ stretching vibration of ester group (due to presence of three carbonyl group in the monomer AMC and VAc) and sharp band at $1260 \mathrm{~cm}^{-1}$ and a broad band at $1148 \mathrm{~cm}^{-1}$ are assigned $\mathrm{C}-\mathrm{O}$ stretching vibration of ester group. Two strong bands at 1502 and $1585 \mathrm{~cm}^{-1}$ are observed which the characteristic absorptions of phenyl ring. As the content of AMC in the copolymers decreases the intensities of these peaks also decreases. The absence of $1630 \mathrm{~cm}^{-1}$ absorption in the polymers is indicative of the participation of the vinyl group in the polymerization.

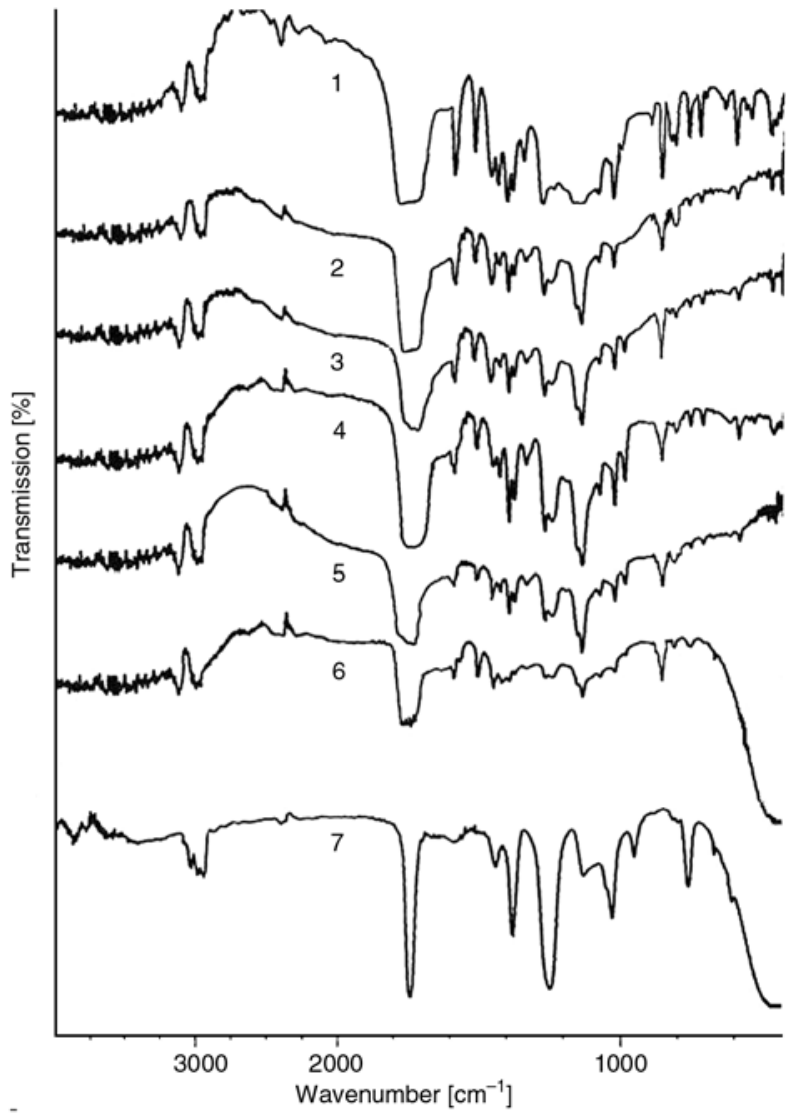

Figure 3. IR spectra of $\mathrm{P}(\mathrm{AMC}), \mathrm{P}(\mathrm{VAc})$ and copolymers

\subsection{Copolymer composition and monomer reactivity ratio}

The average compositions of the copolymer samples were determined by ${ }^{1} \mathrm{H}-\mathrm{NMR}$ spectra. The assignment of the resonance peaks in the in the ${ }^{1} \mathrm{H}$ NMR spectrum leads to accurate evaluation of each monomeric content incorporated into the copolymer chains. Thus, the mole fraction of AMC in the copolymer was calculated by measuring the integrated peak height of aromatic protons of AMC to that of total aliphatic protons in the copolymer as described in Equation (1):

$\therefore C=\frac{\text { Intensity of aromatic protons }\left(I_{A r}\right)}{\text { Intensity of aliphatic protons }\left(I_{A l}\right)}$

The following expression (Equation (2)) is used to determine the composition of the copolymers. Let $m_{1}$ be the mole fraction of AMC and $1-m_{1}$ be that of VAc. AMC contains three aromatic protons and seven aliphatic protons, and VAc contains six aliphatic protons (Equation (2)). 
$\therefore C=\frac{3 m_{1}}{7 m_{1}+6\left(1-m_{1}\right)}$

This on simplification gives (Equation (3)):

$\therefore m_{1}=\frac{6 C}{3-C}$

Based on Equation (3), the mole fractions of AMC in the copolymers were determined by measuring the integral peak height of aromatic proton and aliphatic proton signals. Table 1 gives the values of $C$ and the corresponding mole fractions of $\mathrm{AMC}$ in the copolymers.
From the monomer feed ratios and the copolymer composition, the reactivity ratios of $\mathrm{AMC}$ and $\mathrm{VAc}$ were determined by the application of conventional linearization methods, such as Fineman-Ross (F-R) [17], Kelen-Tüdős (K-T) [18] and extended KelenTüdős (Ext. K-T) [19]. The F-R and K-T parameters for the copolymers are presented in Table 2 and those for Ext. K-T are shown in Table 3. The reactivity ratios values obtained from F-R plot, K-T and Ext. K-T plots (Figures 4a, 4b and 4c) are presented in Table 4.

The reactivity ratio values indicate that the $\mathrm{AMC}$ radical favors its own monomer rather than VAc. Generally the neutral olefin molecules and those

Table 2. F-R and K-T parameters for copolymers of AMC with VAc

\begin{tabular}{|c|c|c|c|c|c|c|c|c|c|}
\hline $\begin{array}{c}\text { Polymer } \\
\text { No. }\end{array}$ & $\begin{array}{c}\operatorname{AMC}\left(\mathbf{M}_{1}\right) \\
{[\text { mole] }}\end{array}$ & $\begin{array}{c}\text { VAc }\left(\mathbf{M}_{2}\right) \\
{[\text { mole }]}\end{array}$ & $\begin{array}{c}\text { Conversion (w) } \\
{[\%]}\end{array}$ & $\mathbf{x}$ & $\mathbf{y}$ & $\mathbf{F}$ & G & $\xi$ & $\eta$ \\
\hline 2 & 0.5 & 0.5 & 9.12 & 1.00 & 0.969 & 1.033 & -0.033 & 0.799 & -0.025 \\
\hline 3 & 0.4 & 0.6 & 8.83 & 0.67 & 0.745 & 0.597 & -0.228 & 0.697 & -0.266 \\
\hline 4 & 0.3 & 0.7 & 8.72 & 0.43 & 0.548 & 0.334 & -0.353 & 0.563 & -0.595 \\
\hline 5 & 0.2 & 0.8 & 9.01 & 0.25 & 0.364 & 0.172 & -0.436 & 0.398 & -1.012 \\
\hline 6 & 0.1 & 0.9 & 8.98 & 0.11 & 0.189 & 0.065 & -0.476 & 0.20 & -1.467 \\
\hline
\end{tabular}

where, $x=M_{1} / M_{2} ; y=m_{1} /\left(1-m_{1}\right) ; F=x^{2} / y ; G=x[(y-1) / y] ; \alpha=\sqrt{F_{M} \cdot F_{m}}=0.272 ; \xi=F /(\alpha+F) ; \eta=G / \alpha+F$

Table 3. Extended K-T parameters for copolymers of AMC with VAc

\begin{tabular}{|c|c|c|c|c|c|c|c|}
\hline Polymer No. & $\boldsymbol{\zeta}_{\mathbf{2}}$ & $\boldsymbol{\zeta}_{\mathbf{1}}$ & $\mathbf{z}$ & $\mathbf{F}$ & $\mathbf{G}$ & $\boldsymbol{\xi}$ & $\boldsymbol{\eta}$ \\
\hline 2 & 0.090 & 0.092 & 1.034 & 0.965 & 0.031 & 0.783 & 0.025 \\
\hline 3 & 0.079 & 0.088 & 1.113 & 0.595 & -0.234 & 0.690 & -0.271 \\
\hline 4 & 0.076 & 0.093 & 1.234 & 0.343 & -0.385 & 0.563 & -0.630 \\
\hline 5 & 0.072 & 0.094 & 1.298 & 0.190 & -0.523 & 0.416 & -1.143 \\
\hline 6 & 0.071 & 0.104 & 1.478 & 0.073 & -0.567 & 0.216 & -1.664 \\
\hline
\end{tabular}

where, $\mu=\mu_{2} / \mu_{1}=0.374 ; \zeta_{2}=w(\mu+x / \mu+y) ; \zeta_{1}=\zeta_{2}(y / x) ; z=\log \left(1-\zeta_{1}\right) / \log \left(1-\zeta_{2}\right) ; F=y / z^{2} ; G=(y-1) / z ; \alpha=\sqrt{F_{M} \cdot F_{m}}=0.2669$; $\xi=F /(\alpha+F) ; \eta=G / \alpha+F$
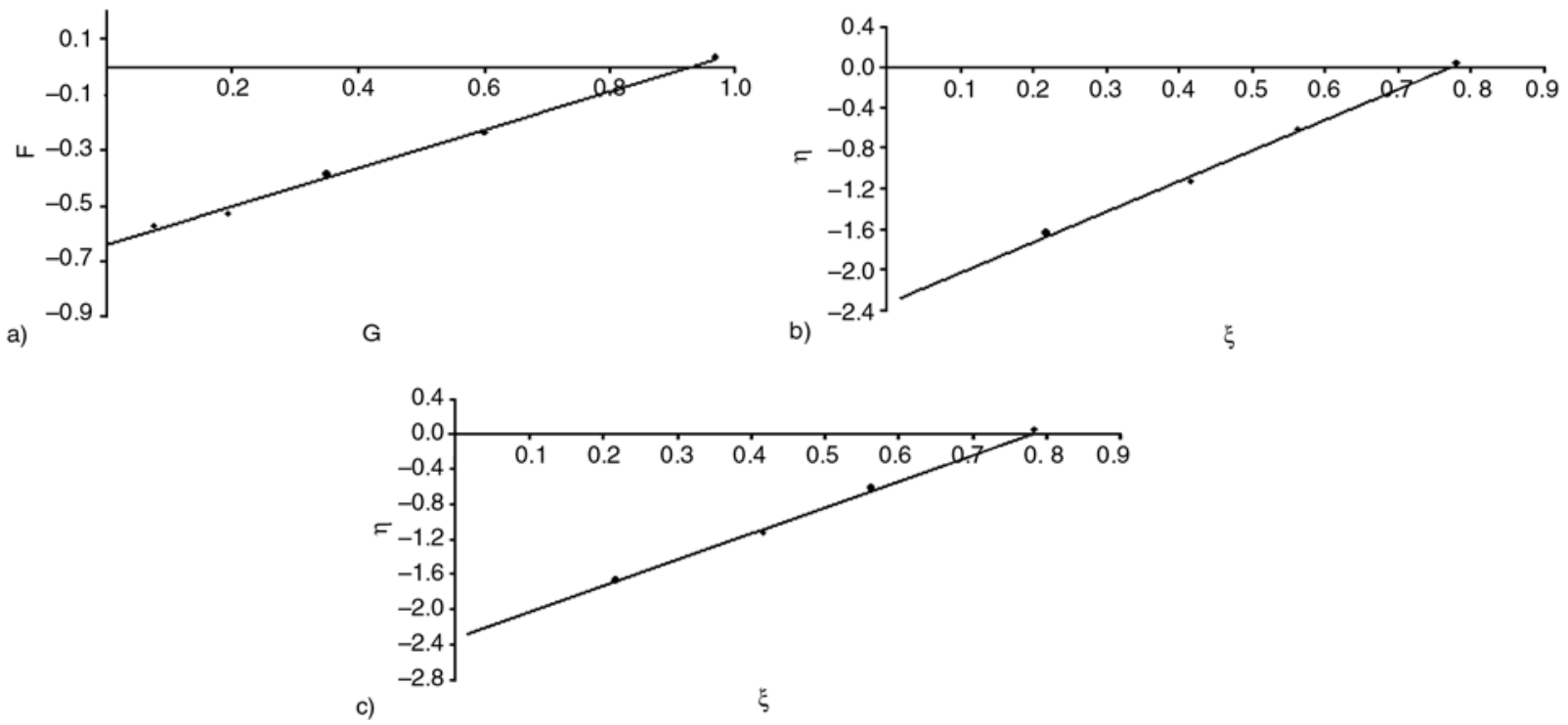

Figure 4. $\mathrm{P}(\mathrm{AMC}-\mathrm{co}-\mathrm{VAc})$ system (a) Finemann-Ross plot, (b) Kelen-Tüdős plot and (c) Extended Kelen-Tüdős plot 
Table 4. Monomer reactivity ratio by different linearization methods

\begin{tabular}{|l|c|c|c|}
\hline \multicolumn{1}{|c|}{ Method } & $\boldsymbol{r}_{\mathbf{1}}$ & $\boldsymbol{r}_{\mathbf{2}}$ & $\boldsymbol{r}_{\mathbf{1}} \boldsymbol{r}_{\mathbf{2}}$ \\
\hline Fineman-Ross & 0.6924 & 0.6431 & 0.6173 \\
\hline Kelen-Tüdős & 0.6776 & 0.6374 & 0.6690 \\
\hline Extended Kelen-Tüdős & 0.6657 & 0.6256 & 0.6530 \\
\hline
\end{tabular}

$r_{1}$ and $r_{2}$ are the reactivity ratios of AMC and VAc, respectively

olefin molecules containing moderately electrondonating or electron-withdrawing groups favor free radical polymerization. VAc consists of electron withdrawing acetate group attached to olefin molecule while AMC consist of electron withdrawing phenyl group. But the net charge on AMC is less compared to VAc and thus is more reactive. Also stearic effects and overall polarity of molecule plays a key role in relative reactivity of monomers. Since the $r_{1}$ and $r_{2}$ values are less than one, this system gives rise to azeotropic polymerization at a particular composition of the monomers which is calculated using Equation (4) [20]:

$$
N_{1}=\frac{\left(1-r_{2}\right)}{\left(2-r_{1}-r_{2}\right)}=0.537
$$

When the mole fraction of AMC in the feed is 0.537 , the copolymer formed will have the same composition as that of feed. When the mole fraction of the feed is less than 0.537 with respect to AMC, the copolymer is richer in this monomeric unit. When the mole fraction of AMC in the feed is above 0.537 , the copolymer is relatively richer in VAc monomeric unit.

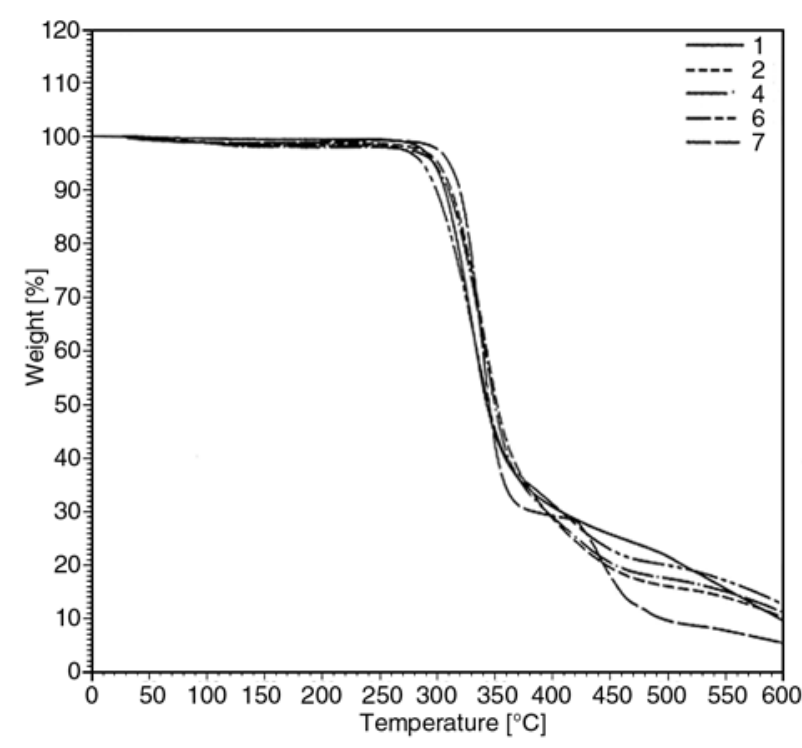

Figure 5. TG curves of $\mathrm{P}(\mathrm{AMC}), \mathrm{P}(\mathrm{AMC}-\mathrm{co}-\mathrm{VAc})$ and $\mathrm{P}(\mathrm{VAc})$

\subsection{Thermogravimetric analysis}

TGA curves for $\mathrm{P}(\mathrm{AMC}), \mathrm{P}(\mathrm{VAc})$ and $\mathrm{P}(\mathrm{AMC}-\mathrm{co}-$ $\mathrm{VAc}$ ) are shown in Figure 5. The thermograms clearly indicate that $\mathrm{P}(\mathrm{AMC})$ and $\mathrm{P}(\mathrm{AMC}-\mathrm{co}-\mathrm{VAc})$ undergoes single step degradation where as $\mathrm{P}(\mathrm{VAc})$ undergoes double step degradation. The decomposition temperature of different copolymers ranges between to $263-567^{\circ} \mathrm{C}$. The activation energy found by Broido's method [21] lies in the range of 38 to $50 \mathrm{~kJ} \cdot \mathrm{mole}^{-1}$ whereas integral procedural decomposition temperature found by Doyle's method [22] lies in the range of $348-358^{\circ} \mathrm{C}$. The detailed result are shown in Table 5 and indicates that value of $E_{A}$ and IPDT does not depend on $\mathrm{AMC}$ content in the copolymers i.e. it may increase or decrease randomly with decrease in AMC content.

Table 5. TGA, GPC and viscosity data for homo and copolymers of AMC with VAc

\begin{tabular}{|c|c|c|c|c|c|c|c|c|c|}
\hline $\begin{array}{c}\text { Polymer } \\
\text { No. }\end{array}$ & $\begin{array}{c}\text { Decomposition } \\
\text { temperature } \\
\text { range } \\
{\left[{ }^{\circ} \mathrm{C}\right]}\end{array}$ & $\begin{array}{l}\mathrm{T}_{50^{\mathrm{a}}} \\
{\left[{ }^{\circ} \mathbf{C}\right]}\end{array}$ & $\begin{array}{c}\text { IPDT }^{\mathbf{b}} \\
{\left[{ }^{\circ} \mathbf{C}\right]}\end{array}$ & $\begin{array}{c}\text { Activation } \\
\text { energy } \\
\left(\mathbf{E}_{\mathbf{A}}\right) \\
{\left[\mathrm{kJ} \cdot \mathrm{mole}^{-1}\right]}\end{array}$ & $\bar{M}_{n}$ & $\bar{M}_{w}$ & $\bar{M}_{z}$ & $\begin{array}{c}\text { Poly } \\
\text { dispersity } \\
\text { index } \\
\bar{M}_{w} / \bar{M}_{n}\end{array}$ & $\begin{array}{c}\text { Intrinsic } \\
\text { viscosity }(\eta) \\
{\left[\mathrm{dl}^{-} \cdot \mathrm{g}^{-1}\right]}\end{array}$ \\
\hline 1 & $280-403$ & 341 & 348 & 43 & 31230 & 47070 & 63470 & 1.507 & 0.212 \\
\hline 2 & $280-450$ & 351 & 355 & 40 & 30430 & 44590 & 59600 & 1.465 & 0.196 \\
\hline 4 & $286-455$ & 352 & 358 & 38 & 26060 & 37990 & 51250 & 1.458 & 0.168 \\
\hline 6 & $263-458$ & 343 & 348 & 39 & 21840 & 30320 & 40050 & 1.388 & 0.138 \\
\hline 7 & $\begin{array}{l}283-373 \\
419-567\end{array}$ & 338 & 358 & 50 & 20580 & 27130 & 36380 & 1.318 & 0.108 \\
\hline
\end{tabular}

atemperature for $50 \%$ weight loss

bintegral procedural decomposition temperature by Doyle's method cby Broido's method 

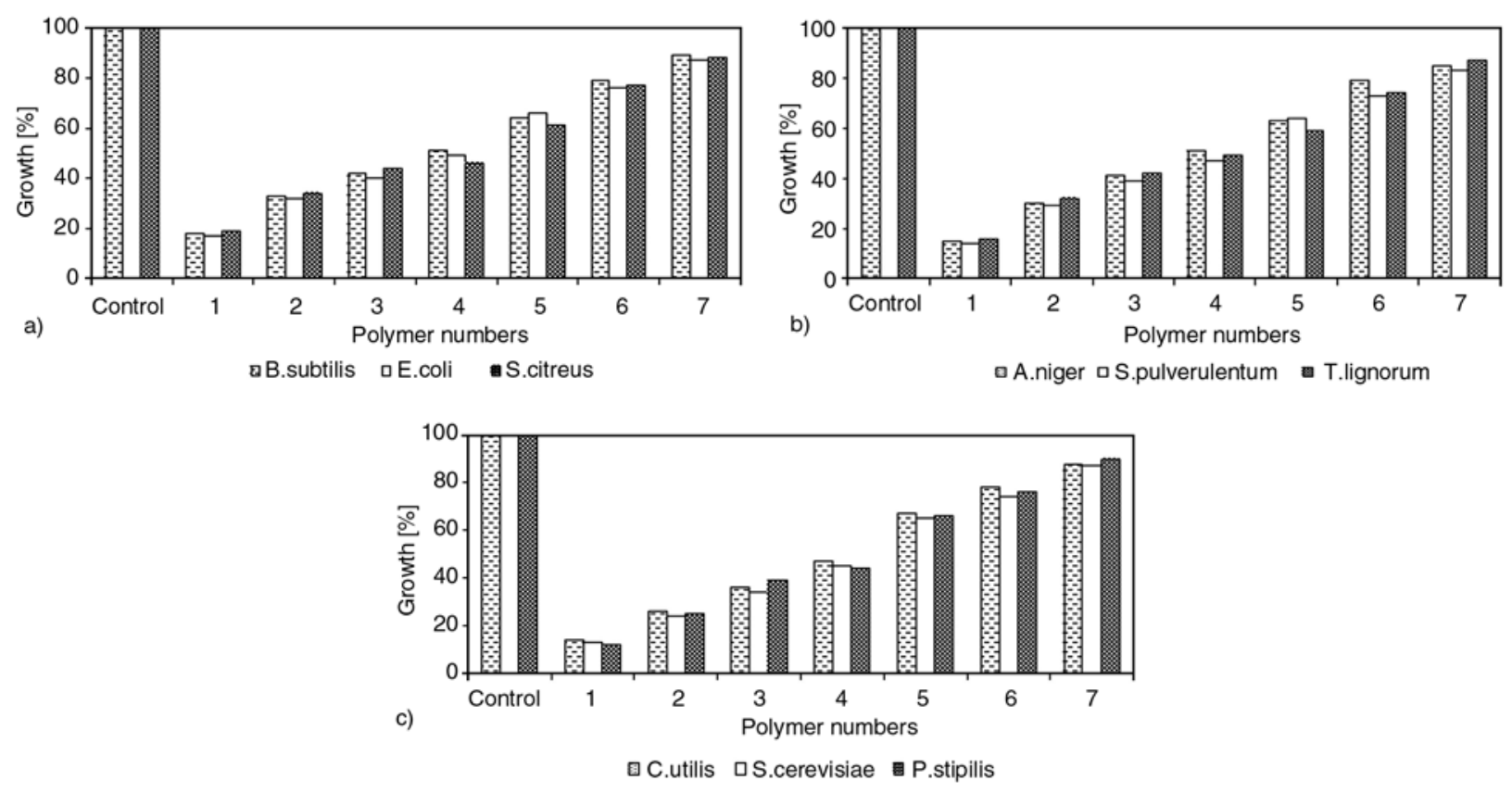

Figure 6. Effect of $\mathrm{P}(\mathrm{AMC}), \mathrm{P}(\mathrm{AMC}-\mathrm{co}-\mathrm{VAc})$ and $\mathrm{P}(\mathrm{VAc})$ on growth of (a) bacteria, (b) fungi and (c) yeast

\subsection{Molecular weights}

The number and weight average molecular weight of $\mathrm{P}(\mathrm{AMC})$ and $\mathrm{P}(\mathrm{AMC}-\mathrm{co}-\mathrm{VAc})$ were determined by gel permeation chromatography and are presented in Table 5. The polydispersity indices of different polymers lies in the ranges 1.318 to 1.507 respectively whereas intrinsic viscosity $[\eta]$ ranges from 0.108 to $0.196 \mathrm{dl} \cdot \mathrm{g}^{-1}$. The results indicate that with decrease in the AMC content in the copolymers, molecular weights, polydispesity and viscosity decreases to the considerable extent.

\subsection{Antimicrobial activity}

The results obtained for antimicrobial activity of the $\mathrm{P}(\mathrm{AMC}), \mathrm{P}(\mathrm{AMC}-\mathrm{co}-\mathrm{VAc})$ and $\mathrm{P}(\mathrm{VAc})$ are presented in Figures 6a, 6b and 6c. P(AMC) allows $17-19 \%$ growth of bacteria, where as its copolymers favors $24-78 \%$ growth. Fungi in presence of $\mathrm{P}(\mathrm{AMC})$ register around $14-16 \%$ growth, while 29-79\% growth for fungi is observed in the copolymers. Yeast in presence of $\mathrm{P}(\mathrm{AMC})$ shows $12-14 \%$ growth, while $24-78 \%$ growth for yeast is observed in copolymers. The $\mathrm{P}(\mathrm{AMC})$ is found to be most effective in inhibiting the growth of microorganisms; these may be traced due to heterocyclic moiety of coumarin. As the percentage of monomer AMC increases in the copolymer the antimicrobial activity of the copolymers increases.

\section{Conclusions}

New acrylate based homo and copolymers were synthesized by free radical solution polymerization technique. The monomers and copolymers were characterized by spectroscopic methods. The reactivity ratio of AMC $\left(r_{1}\right)$ is greater than VAc $\left(r_{2}\right)$ and the product of $r_{1} r_{2}$ is less than one. This shows that the monomers were distributed in the copolymer chain in random fashion. Thermo gravimetric analysis showed that $\mathrm{P}(\mathrm{AMC})$ and $\mathrm{P}\left(\mathrm{AMC}-\mathrm{Co}^{-}\right.$ VAc) undergoes single step decomposition where as $\mathrm{P}(\mathrm{VAc})$ undergoes double step decomposition. All the polymers showed moderate thermal stability. The number average molecular weight and weight average molecular weight were in the range of 20580 to 31230 and 27130 to 47070 respectively. Molecular weight increases with increase in content of AMC in copolymer. Presence of 4methylcoumarin group in the polymer chain imparts antimicrobial properties to the polymers. The results of antimicrobial activity shows that the copolymers containing AMC shows excellent growth inhibition against all microorganisms and as AMC content in the copolymers increases the growth inhibition of microorganisms also increases. 


\section{References}

[1] Mark H. F., Bikales N. M., Overberger C. G., Menges G.: Encyclopedia of polymer science and engineering. Wiley, New York (1986).

[2] Gatica N., Natali F., Alejandra O., Deodato R.: Synthesis and characterization of functionalized vinyl copolymers I: Structure-monomer reactivity relationship in copolymers containing $\mathrm{N}$-vinyl-2-pyrrolidone moieties. Journal of the Chilean Chemical Society, 50, 581-585 (2005).

[3] Gatica N., Fernandez N., Opazo E., Alegria S., Gargalio L., Radic D.: Synthesis and characterization of functionalized vinyl copolymers: Electronegativity and comonomer reactivity in radical copolymerization. Polymer International, 52, 1280-1286 (2003).

[4] Vogl O., Albertsson A. C., Janovic Z.: New developments in speciality polymers: Polymeric stabilizers. Polymer, 26, 1288-1296 (1985).

[5] Czech Z., Butwin A., Herko E., Hefczye B., Zawadiak J.: Novel azo-perester radical initiators used for synthesis of acrylic pressure sensitive adhesives. Express Polymer Letters, 2, 277-283 (2008).

[6] Pazhanisamy P., Reddy B. S. R.: Copolymers of Ncyclohexylacrylamide and $n$-butyl acrylate: Synthesis, characterization, monomer reactivity ratio and mean sequence length. Express Polymer Letters, 1, 391-396 (2007).

[7] Nuessle A. C., Kine B. B.: Acrylic resin in textile processing. Industrial and Engineering Chemistry, 35, 1287-1293 (1953).

[8] Ye W., Leung M. F., Xin J., Kwong T. L., Lee D. K. L., Li P.: Novel core-shell particles with poly(n-butyl acrylate) cores and chitosan shells as an antibacteial coating for textiles. Polymer, 46, 10538-10543 (2005).

[9] Osawa E., Nozawa T., Kurihara O.: Synthesis of polymerizable fluorescent brightening agents and photodecomposition of their copolymers with acrylonitrile and methyl acrylate (in Japanese). Kogyo Kogaku Zasshi, 68, 519-524 (1965).

[10] Lu Z. Y., Yuan T. S., Chen Y. L., Wei X. Q., Xie M. G., Zhu W. G.: Synthesis of a novel blue light emitting polymer material bearing coumarin pendants. Chinese Chemical Letters, 13, 674-677 (2002).
[11] Chen Y., Chen Y-H., Wang J. H.: Radical copolymerization behaviors of styrene and coumarin. Journal of Polymer Research, 1, 295-303 (1994).

[12] Lindsay G. A., Hoover J. M.: Near $T_{g}$ relaxation behaviour in non-linear optical polymers and views on physical sign. Polymer Preprints, 34, 771-772 (1993).

[13] Vogel A. I., Tatchell A. R., Furniss A. J., Hannaford P. W., Smith P. W. G.: Vogel's textbook of practical organic chemistry. Pearson Education, Singapore (1989).

[14] Stempel G. H., Cross R. P., Mareioll R. P.: Preparation of acryloyl chloride. Journal of American Chemical Society, 72, 2299-2300 (1950).

[15] Patel J. N., Patel M. V., Patel R. M.: Copolymers of 2,4-dichlorophenyl methacrylate with styrene: synthesis, thermal properties and antimicrobial activity. Journal of Macromolecular Science Part A: Pure and Applied Chemistry, 42, 71-83 (2005).

[16] Patel M. G., Patel H. J., Patel J. R., Patel K. H., Patel R. M.: Development and applications of novel acrylic copolymers. International Journal of Polymeric Materials, 57, 165-176 (2008).

[17] Fineman M., Ross S. D.: Linear method for determining monomer reactivity ratios in copolymerization. Journal of Polymer Science, 5, 259-265 (1950).

[18] Kelen T., Tüdős F.: Analysis of the linear methods for determining copolymerization reactivity ratios: A new improved linear graphic method. Journal of Macromolecular Science Part A: Pure and Applied Chemistry, 9, 1-27 (1975).

[19] Kelen T., Tüdős F., Turcsányi B., Kennedy J. P.: Analysis of the linear method for determining and critical re-examination of cabocationic copolymerization data. Journal of Polymer Science: Polymer Chemistry, 15, 3041-3074 (1977).

[20] Gowariker V. R., Viswanathan N. V., Sreedhar J.: Polymer science. New Age International, New Delhi (1986).

[21] Broido A.: A simple, sensitive graphical method of treating thermogravimetric analysis data. Journal of Polymer Science Part A: Polymer Physics, 27, 17611774 (1969).

[22] Doyle C. D.: Estimating thermal stability of experimental polymers by empirical thermogravimetric analysis. Analytical Chemistry, 33, 77-79 (1961). 